\title{
Julian Assange, the UN and the limits of Detention
}

\section{Binoy Kampmark ${ }^{1}$}

The idea of arbitrary detention and how it violates various international protocols is a pressing theme of international juridical and philosophical opinion. Such conduct is an expression of unjustified political control by States over citizens, and speaks to the ever present dangers of power unwatched and unregulated. The political prisoner remains the classic figure of this enterprise, both a target and a threat. What is less examined in this regard is how that control manifests itself, a matter that has proven to be a far more complex affair. This paper examines that debate by looking at the case of Julian Assange and his claim that he is being arbitrarily detained in the Ecuadorean embassy in London. The legal claim that he is not is critiqued as being unduly positivist and in need of correction, referring to the findings of the UN Working Group on Arbitrary Detention in February 2015. [Article copies available for a fee from The Transformative Studies Institute. E-mail address: journal@transformativestudies.org Website: http://www.transformativestudies.org (C2018 by The Transformative Studies Institute. All rights reserved.]

KEYWORDS: Arbitrary Detention, Legal Positivism, Julian Assange

"Should the UN announce tomorrow that I have lost my case against the United Kingdom and Sweden I shall exit the embassy at noon on Friday to accept arrest by British police as there is no meaningful prospect of further appeal."

Julian Assange, Twitter, Feb 5, 2016.

\footnotetext{
${ }^{1}$ Binoy Kampmark, Ph.D., is a Senior Lecturer in the School of Global, Urban and Social Studies, RMIT University, Melbourne. He was a Commonwealth Scholar at Selwyn College, University of Cambridge, and is a contributing editor to CounterPunch. Address correspondence to: Dr. Binoy Kampmark, RMIT University, Melbourne, Australia 3000; e-mail: bkampmark@gmail.com.
} 